\title{
O estudo do universo escolar através da voz dos jovens: o grupo de discussão
}

\author{
Maria Cecília Pereira dos Santos \\ Escola Secundária de Gondomar, Portugal
}

\begin{abstract}
Resumo
Este texto, centrado numa pesquisa que decorreu num determinado contexto escolar, visa realçar a importância da utilização da metodologia qualitativa em investigação e mostrar as potencialidades inerentes ao grupo de discussão para a recolha de dados, sobretudo quando os interlocutores são jovens estudantes do Ensino Secundário. O presente artigo pretende incidir sobre algumas dimensões consideradas fulcrais para se levar a efeito um trabalho de campo utilizando o grupo de discussão. Após uma breve incursão sobre alguns autores cujos trabalhos têm vindo a privilegiar esta técnica de recolha de informação no estudo de diferentes contextos sócio-educativos, procedese a uma reflexão sucinta sobre suas potencialidades e alguns dos seus limites.
\end{abstract}

Palavras-chave

Grupo de discussão; Jovens; Universo escolar; Experiência

\section{Introdução}

Este artigo decorre da realização de um trabalho académico, no âmbito de um projecto de Doutoramento em Educação, na Área de Conhecimento de Sociologia da Educação, que privilegiou o grupo de discussão como a principal técnica para a recolha da informação durante o tempo em que decorreu o trabalho de campo. 
O nosso estudo teve como principais interlocutores alguns jovens alunos de Ensino Secundário e, através da nossa experiência no terreno, fomos construindo e enfortalecendo a convicção de que o grupo de discussão se apresenta como uma técnica altamente favorável aos estudos sociológicos, nomeadamente aqueles que procuram compreender os dilemas e as diferentes perspectivas sociais e escolares dos actores, dando voz a alguns grupos juvenis. Acresce que quando colocados perante uma situação de diálogo e de confronto de ideias e de saberes, esses jovens com quem trabalhámos reagiram com entusiasmo e oportunidade às questões e/ou tópicos aglutinadores da discussão sobre o universo escolar. Este facto acabou por favorecer a reflexão individual e colectiva (génese de um processo analítico de (re)construção das suas experiências), que permitiu chegar a opiniões assumidas por todos e por cada um em particular. Assim, através do recurso a esta técnica, o grupo de discussão, as análises heterogéneas e plurais que cada um dos participantes teve ocasião de levar a efeito sobre determinadas perspectivas, quer subjectivas quer escolares, transformaram cada abordagem e reflexão individual num sentir crítico colectivo assumido por todos.

De facto, o trabalho de campo que levámos a efeito permitiu concluir que os jovens alunos chegaram através do debate de ideias e da reflexão crítica à construção comum de opiniões acerca dos vários tópicos propostos que nos interessavam ver discutidos como, entre outros, a experiência escolar, as expectativas para o futuro, as práticas pedagógicas, a avaliação escolar, a selecção. Enfim, um conjunto bastante alargado de possibilidades que, numa fase final da pesquisa, permitiu concluir acerca das vantagens da opção tomada relativamente à utilização do grupo de discussão. Sobretudo porque se foi construindo, face-a-face, sessão a sessão, um sentir colectivo sobre os assuntos discutidos. Por exemplo, foi possível afirmar que um dos principais dilemas de uma grande maioria dos jovens estudantes do Ensino Secundário passava pela difícil tarefa de conciliar a vida juvenil e a vida escolar e, simultaneamente, conseguir obter classificações para ingressar num curso de Ensino Superior público.

No entanto, no presente artigo, a nossa preocupação incidirá, apenas, sobre a técnica utilizada, isto é, algumas dimensões que considerámos fundamentais para se levar a efeito um trabalho de campo utilizando o grupo 
de discussão. Sendo assim, após uma breve incursão sobre alguns autores cujos trabalhos têm vindo a privilegiar o grupo de discussão no estudo de diferentes contextos sócio-educativos, seguir-se-á uma reflexão sucinta sobre as suas potencialidades e os seus limites.

\section{O Grupo de Discussão - a (re)emergência de uma técnica de investigação qualitativa para a recolha de informação em contexto escolar}

Quando pretendemos levar a efeito uma pesquisa no âmbito do campo específico da Sociologia da Educação, e chegados ao momento da definição dos contextos escolares a estudar e dos actores com quem queremos desenvolver o nosso trabalho de campo (próximo dos estudos que privilegiam a etnografia para descrever e compreender o «modo de vida» de um grupo de indivíduos), a escolha e a selecção do tipo de metodologia (de índole quantitativa e/ou de índole qualitativa) e as técnicas de investigação (inquéritos, entrevistas, grupos de discussão) a utilizar para chegar à recolha da informação podem, eventualmente, colocar alguns dilemas ao investigador, sobretudo quando este sabe, por experiência, que esses contextos são espaços onde as acções e interacções subjectivas se produzem e se interseccionam com relativa naturalidade e onde inúmeras dimensões se cruzam configurando mudanças frequentes ${ }^{1}$.

A complexidade, a diversidade e a interacção de determinadas situações educativas podem propiciar um terreno propício a determinados enfoques relativos à teoria e à prática investigativa sobre o universo escolar. Por outro lado, a pesquisa científica tem vindo a reflectir as mudanças operadas na sociedade que obrigam os investigadores a procurar dentro da própria ciência perspectivas inovadoras que respondam com mais acuidade aos estudos de algumas situações problemáticas.

Neste sentido, trabalhos recentes (por exemplo, Callejo, 2001; Fabra \& Domènech, 2001; Ortega, 2005) têm vindo a acentuar e a valorizar o grupo de discussão como uma técnica a utilizar e a desenvolver para a recolha de informação, sobretudo no estudo de situações revestidas de alguma complexidade como as que são vivenciadas em ambientes escolares, embora, como sublinha Magdalena Ortega, ao longo do tempo, esta técnica 
tenha sido pouco utilizada e valorizada pelos estudos de âmbito sócioeducativo. Assim,

Neste sentido, precisamos de investigações que utilizem o grupo de discussão como técnica para a recolha de informação que se centrem em determinados campos ou âmbitos de aplicação. Por exemplo, centrando-nos no âmbito educativo, o grupo de discussão pode trazer aspectos interessantes se se aplicar ao estudo de problemáticas que se revistam de complexidade, como o estudo das atitudes dos estudantes face a reformas dos planos de estudo, a análise da cultura institucional [...], de problemáticas e/ou necessidades de certos grupos relativa à inserção socioprofissional... (Ortega, 2005: 20).

Para esta investigadora, no âmbito da intervenção psicopedagógica e sócio-educativa, o recurso a esta técnica pode permitir responder a alguns objectivos que se relacionam com a análise e compreensão de situações educativas, com os processos de ensino/aprendizagem, com a resolução de conflitos, com a qualidade das instituições não só do ponto de vista dos jovens alunos, mas também de outros actores educativos como os professores, os pais/encarregados de educação (cf. Ortega, 2005: 36).

Mas, o grupo de discussão, apesar de ser uma técnica de conversação que faz parte da família das pesquisas de índole qualitativa e situando-se próxima das entrevistas em grupo (focus group), distingue-se destas e adquire um carácter próprio. Ou seja, na esteira de alguns autores, nomeadamente Callejo (2001), que têm levado a efeito pesquisas utilizando o grupo de discussão, o que encontrámos de particular e inovador na aplicação desta técnica no nosso trabalho de campo (e que a poderá distinguir das entrevistas em grupo), reside no facto de durante o debate, perante um tópico de discussão, cada um dos elementos do grupo ter tido a possibilidade de apresentar, de defender, de construir e de descontruir os seus pontos de vista numa lógica de interacção que, gradualmente, se tornou mais profunda e complexa, chegando-se, por fim, naturalmente, a um conjunto de opiniões comuns a todos os intervenientes.

George Gaskell, por exemplo, não deixa de aludir à relevância das entrevistas para a compreensão de contextos sociais específicos, sugerindo:

O emprego da entrevista qualitativa para mapear e compreender o mundo da vida dos respondentes é o ponto de entrada para o cientista social que introduz, então, esquemas interpretativos para compreender as narrativas dos atores em termos mais conceptuais e abstratos [...]. A entrevista qualitativa, pois, fornece os dados básicos para o desenvolvimento e a compreensão das relações entre 
os atores sociais e sua situação. O objectivo é uma compreensão detalhada das crenças, atitudes, valores e motivações, em relação aos comportamentos das pessoas em contextos sociais específicos (Gaskell, 2002: 64).

As entrevistas em grupo, denominadas também por grupo focal, podem ser comparadas ao conceito de Habermas de esfera pública ideal, ou seja, a um debate aberto, acessível a todos os intervenientes e onde não são valorizadas as diferenças de estatuto entre os actores. Estes debatem questões do seu interesse produzindo uma discussão racional atravessada, no entanto, por emoções e experiências pessoais (cf. Gaskell, 2002: 79).

Observa-se, assim, que a entrevista em grupo parece bastante próxima do grupo de discussão, o que não deixa, actualmente, de constituir um problema de complexidade terminológica que pode afectar a definição e até a compreensão do que se entende por grupo de discussão, pois em algumas traduções da língua inglesa ou da língua francesa para a língua castelhana o Grupo Focal e o Grupo de Discussão são considerados sinónimos (cf. Callejo, 2001: 16).

Entretanto, a necessidade de clarificação, de formalização e de justificação teórica do grupo de discussão começa a impor-se com mais acuidade, facto que leva alguns investigadores a estabelecer comparações e diferenças com outras técnicas, anteriormente referidas, que pelas suas características se aproximam daquele, concluindo-se assim que ora aparece relacionado com a dinâmica do grupo, ora com o porquê e o como dos discursos produzidos pelos participantes ${ }^{2}$.

Mas, à parte as diferenças teóricas encontradas, parece ter-se chegado a alguns consensos, por exemplo, entre os autores de língua inglesa, de quem fala Javier Callejo, quando afirmam que a "situação grupal, real ou imaginária, facilita o intercâmbio de posições dos indivíduos [que] no grupo estão no centro da lógica do intercâmbio. [E, assim, partindo da perspectiva dos actores,] possibilita-se a construção do comum entre os indivíduos" (Callejo, 2001: 37) ${ }^{3}$.

Por outras palavras, o grupo de discussão (tal como as entrevistas em profundidade de tipo semi-estruturado com um único respondente e as histórias de vida) ao trabalhar com a fala, e situando-se dentro das perspectivas do discurso social, pode permitir chegar a um tipo de informação diferente daquela a que se chegaria com o recurso a outras técnicas ${ }^{4}$. 
Tal como não deixa de chamar a atenção Peter Woods, qualquer investigação requer uma planificação prévia, mas o que pode distinguir a recolha de dados num trabalho qualitativo é que essa "se move dentro de uma margem de flexibilidade e relativamente sem compromisso" (Woods, 1993: 193). Parece ser também esta uma das dimensões imputáveis à técnica de pesquisa que temos vindo a realçar. Ou seja, a informação recolhida desvenda e dá a conhecer os aspectos internos da problemática em debate através da riqueza das subjectividades partilhadas e assimilados pelo grupo para a construção do seu próprio discurso, num ambiente onde a autonomia, a liberdade e a reflexão crítica permitem ajustar, articular e integrar perspectivas individuais e colectivas num vaivém constante que se estabelece entre os diferentes membros do grupo (cf. Ortega, 2005: 24).

$\mathrm{Na}$ perspectiva dos investigadores anteriormente mencionados, o grupo de discussão, como prática para a compreensão dos "processos psicossociais", tem vindo a ser reactivado nos últimos anos (algumas décadas depois do grande êxito alcançado pelos trabalhos de Merton no âmbito da investigação de mercados, durante os anos quarenta) como uma ferramenta muito importante ao serviço da investigação qualitativa, particularmente no estudo de situações onde as subjectividades e a intersubjectividades se cruzam, nomeadamente no universo escolar.

Deste modo, dois investigadores chegam à caracterização do grupo de discussão realçando os seguintes aspectos:

O grupo de discussão é constituído por um conjunto reduzido de pessoas, reunidas com o propósito de interactuar numa conversa sobre temas objecto de investigação, durante um período de tempo que oscila entre uma hora e hora e meia. É precisamente essa interacção que distingue o grupo de discussão e o que proporciona o seu interesse e a sua força. A discussão, efectivamente, não tem como objectivo a busca de consenso entre os participantes; o que permite é recolher um grande leque de opiniões e pontos de vista que podem ser tratados extensivamente. A situação de grupo produz a deslocação do controlo da interacção desde o investigador até aos participantes, o que dá uma maior ênfase [...] aos pontos de vista dos participantes, facto que permite um aprofundamento dos temas propostos à discussão, o que dificilmente se consegue de outra maneira (Fabra \& Domènech, 2001: 33-34). 


\subsection{Alguns limites apontados ao Grupo de Discussão}

No entanto, apesar das potencialidades que se reconhecem ao grupo de discussão para a recolha de informação, alguns investigadores não deixam, porém, de alertar para certos limites e debilidades que podem ser encontrados. Limites esses que podem conduzir à consideração de que esta técnica carece de fiabilidade, em virtude do número de pessoas implicadas e da dificuldade de se chegar à generalização dos dados recolhidos ${ }^{5}$.

Embora, na opinião de $\mathrm{M}^{\mathrm{a}}$ - Lluisa Fabra \& Miquel Domènech e de acordo com a nossa própria experiência, pareça ser este um falso problema, visto "as respostas dos membros do Grupo de Discussão não poderem ser consideradas como um reflexo da 'verdade' ou como uma representação fidedigna da 'realidade', mas como um desenvolvimento de perspectivas e de valores socialmente disponíveis recolhidos no conjunto de 'tópicos' que surgem a partir da discussão de grupo" (Fabra \& Domènech, 2001: 40).

Por outro lado, a perspectiva de Javier Callejo sublinha a questão da fiabilidade relacionando-a directamente com a saturação, ou seja, quando os discursos começam a ser redundantes, isto pode ser um critério de fiabilidade das investigações qualitativas. Deste modo, a saturação converte-se no "elemento que termina o trabalho de campo e portanto o desenho empírico da investigação; na base para a representatividade e como referência de fiabilidade" (Callejo, 2001: 161) ${ }^{6}$.

A esta dimensão (que sedimenta a fiabilidade no critério da saturação) pode acrescentar-se, ainda, que o grupo de discussão é uma técnica que apresenta uma "alta validade subjectiva" que subsiste no facto de se devolver a informação ao grupo (cf. Ortega, 2005: 52).

Acrescem, no entanto, outras dimensões que podem, eventualmente, ser consideradas limitativas para um processo de investigação que seleccione esta técnica de recolha de informação. Ou seja, o papel do investigador, simultaneamente moderador, e que pode ter a ver com o maior ou menor grau de controlo por parte do investigador/moderador face ao desenvolvimento da discussão em grupo. Por exemplo, poderá, eventualmente, acontecer no decurso das sessões algum desvio da temática central da discussão por parte dos elementos intervenientes e, em virtude disso, outros temas irrelevantes para aquele objecto de estudo poderem ocupar algum tempo da discussão. 
Na nossa perspectiva, a experiência resultante do trabalho de campo acabou por demonstrar que este é um aspecto que não pode ser descurado, embora se reconheça que a sua (ir)relevância para a prossecução da pesquisa dependerá sempre dos referentes que queremos perseguir ao longo do trabalho de campo e, sobretudo, dos actores com quem trabalhamos. Caberá, então, à experiência e aos conhecimentos do investigador e moderador um papel crucial para minimizar e diluir algumas das dificuldades imprevisíveis e inesperadas (cf. Ortega, 2005: 52).

Por outro lado, a escolha do lugar, a preparação do grupo, a selecção dos participantes são, ainda, dificuldades que se colocam ao investigador quando pretende avançar para o terreno para recolher os seus dados. De facto, durante o nosso trabalho tivemos ocasião de verificar algumas dessas dificuldades, pelo que corroboramos da perspectiva expressa por esta investigadora relativamente à necessidade de se seleccionar um espaço adequado para o decurso das sessões do grupo de discussão, sobretudo porque a liberdade de expressão e a confidencialidade assumem muita relevância não só para o investigador, mas, sobretudo, para os participantes, particularmente no que respeita à garantia inequívoca de poderem expressar livremente as suas opiniões críticas sem constrangimentos.

O Quadro 1 a seguir apresentado pretende ilustrar algumas das potencialidades desta técnica de investigação, ora sinalizados pelos autores a cujos trabalhos tivemos acesso, ora de acordo com a nossa própria experiência e, ainda, algumas limitações possíveis de serem encontradas no decurso do trabalho de campo. 
Quadro 1 - Potencialidades e Limites do Grupo de Discussão

\begin{tabular}{|c|c|}
\hline Potencial idades & Limites \\
\hline $\begin{array}{l}\text { * Interacção entre todos os participantes } \\
\text { * Subjectividades/intersubjectividades (partilha de } \\
\text { experiências, sentimentos, percepções, } \\
\text { intercâmbio de opiniões) } \\
\text { * Integração social, afectiva, pessoal } \\
\text { * Flexibilidade } \\
\text { * Liberdade de expressão } \\
\text { * Espontaneidade } \\
\text { * Não directividade } \\
\text { * Reflexão crítica } \\
\text { * Con strução da realidade social dos actores } \\
\text { * Bidireccionalidade } \\
\text { * Produção de saber científico }\end{array}$ & $\begin{array}{l}\text { * Dificuldades de selecção: } \\
-\quad \text { participantes } \\
\text { - e spaço } \\
\text { * Função do investigador/moderador } \\
\text { * Formação e experiência do investigador } \\
\text { /moderador } \\
\text { * Características pe ssoais e humanas } \\
\text { * Generalização e análise dos dados } \\
\text { * Flexibilidade } \\
\text { * Imprevisibilidade } \\
\text { * Gestão do tempo }\end{array}$ \\
\hline
\end{tabular}

\subsection{Papel e funções do investigador/moderador}

O papel e as funções do investigador/moderador assumem uma relevância incontornável no desenvolvimento satisfatório do grupo de discussão. A este propósito, um trabalho de Robert G. Burgess sublinha a importância crucial do estabelecimento de relações entre o investigador e aqueles que estão a ser investigados, pelo que considera, por exemplo, ser "essencial que o investigador conduza ele próprio as entrevistas, em vez de 'entregar' a tarefa a pessoal remunerado, que não está familiarizado com o contexto e com as pessoas" (Burgess, 1997: 117).

Assim, para que o grupo de discussão possa ter sucesso (e chegar ao fim conservando a totalidade dos elementos com que se iniciou) convirá referir e sublinhar alguns vectores essenciais que dizem respeito ao investigador e que passam, em primeiro lugar, por promover a confiança de todos os participantes, estimular, compreender e aceitar as ideias de todos de modo a integrá-las sem manipular ou cortar o discurso dos actores envolvidos e, em segundo lugar, manter uma postura que, gradualmente, passe de uma não directividade explícita a uma directividade implícita.

$\mathrm{Na}$ nossa opinião, será muito importante ter em consideração essas dimensões, sobretudo quando o grupo é composto por jovens participantes. Neste caso, sublinhar que 
[...] não há respostas correctas ou incorrectas às perguntas que se fazem e insistir, portanto, que tudo o que disserem será considerado valioso. O que se Ihes pede são pontos de vista, opiniões, comentários sobre experiências passadas, relatos de casos de que tenham conhecimento... sempre com o objectivo de recolher informação, nunca de avaliar (Fabra \& Domènech, 2001: 44).

Aliás, nós próprios, em sintonia com o que afirma uma outra autora, consideramos esta prática de investigação qualitativa um processo não directivo, no qual se vai desenvolvendo uma conversa assente num guião, estruturalmente maleável, basicamente constituído por uma "lista de temas". No entanto, todo este processo acaba por exigir do investigador/moderador determinadas características pessoais e humanas para não se impor em demasia exercendo apenas um controlo "suave e não intrusivo".

Também um outro investigador que temos vindo a seguir acaba por considerar o seguinte:

A dinâmica do grupo de discussão se move entre o fomento da reagrupação e o impedimento da consolidação do grupo. O grupo consolida-se face ao observador, face ao que representa o observador-moderador e face a uma situação que é, em princípio, inconsistente, na qual os participantes aguardam instruções. O moderador é o dispositivo da dinâmica quem tem que estar continuamente a analisar o grupo para regular os seus consensos e, de alguma maneira, o processo de reagrupação (Callejo, 2001: 131).

À parte estes requisitos que parecem ser indispensáveis e que estão directamente relacionados com o investigador/moderador, como referíamos, o grupo de discussão exige, para além dos conhecimentos relativos ao processo de investigação, outras características pessoais, de entre as quais destacamos a flexibilidade, a capacidade de observação do grupo, a perspicácia e subtileza para ajudar a desabrochar a interacção entre todos os participantes, a promoção da coesão dentro do grupo, a capacidade de síntese e de recondução de temáticas relevantes que possam surgir aquando da discussão, (cf. Ortega, 2005: 49-50).

No mesmo sentido, outros autores reportando-se à importância da flexibilidade e do carácter aberto das questões, afirmam que, com esta técnica não se pretende

[...] obter respostas a perguntas concretas, mas facilitar o intercâmbio de opiniões e pontos de vista à volta de questões consideradas relevantes e à luz dos objectivos da investigação. [Nesta ordem de ideias,] o guião deve ser uma 
ajuda, não uma exigência pesada que ate de pés e mãos a pessoa que modera. [...] Preferivelmente, as questões devem ser abertas para não condicionar o tipo de resposta que se pode dar. Não se pode esquecer que o objectivo do grupo é recolher o máximo de pontos de vista, e estes aparecem mais facilmente quando não existem modelos para responder às perguntas que se lançam (Fabra \& Domènech, 2001: 42-43).

Assim, a pessoa que conduz o grupo de discussão assume uma função essencial, particularmente no que respeita à responsabilidade de criar um bom ambiente alicerçado na confiança e na confidencialidade que permita o desabrochar natural das intervenções de todos os participantes. Por isso, na perspectiva destes últimos investigadores, as respostas não devem ser avaliadas de correctas ou incorrectas, pois tudo o que for dito, isto é, os comentários, os pontos de vista, as opiniões, as experiências devem ser sempre considerados valiosos para a pesquisa que se pretende levar a cabo (cf. Fabra \& Domènech, 2001: 44).

\section{Concluindo}

Da nossa experiência e do trabalho de campo que elegeu o grupo de discussão para a recolha de informação, poderemos concluir, num primeiro momento, acerca da importância do projecto em que nos envolvemos. Este afigurou-se como um processo altamente dinâmico, alicerçado e enriquecido na e pela escuta das vozes dos jovens alunos que contribuíram, mais uma vez, para se chegar à melhor compreensão dos diferentes contextos escolares. Num segundo momento, cabe realçar que algumas dimensões trabalhadas nos grupos de discussão permitiram evidenciar, ainda que provisoriamente, a existência de uma crescente heterogeneidade discente, facto esse verificável não só ao nível social e cultural, mas sobretudo ao nível das atitudes, das motivações e das expectativas pessoais face à escolaridade e ao futuro profissional.

\section{Notas}

1 Apesar da discussão epistemológica continuar actual acerca das clivagens entre metodologias quantitativas e metodologias qualitativas, julgamos que uma pesquisa de índole qualitativa, mais crítica e com potencialidades formativas poderá potenciar a análise e o tratamento do objecto de estudo, dando-lhe poder e voz, em 
vez de o encarar como simples objecto amorfo e quantificável. Embora saibamos que alguns autores sublinham a necessidade de, adequadamente, se saber "compreender as interpretações que os atores sociais possuem do mundo, pois são estes que motivam o comportamento que cria o próprio mundo social. [E, deste modo,] substituirmos acriticamente nossos próprios pressupostos, pelos dos informantes" (Bauer, Gaskell \& Allum, 2002: 32-33). Também dois autores castelhanos destacam a metodologia qualitativa como um instrumento privilegiado para a investigação social: "Al trabajar com métodos cualitativos, como la etnografia o el análisis del discurso, se subraya cómo éstos, en contraste com los métodos cuantitativos, permiten atender a los significados intersubjetivos, situados social e históricamente, que se dan en la interacción humana, obviando, así, todo intento de buscar hechos objetivos o leys que los expliquen" (Fabra \& Domènech, 2001: 27).

2 Magdalena Ortega afirma, por exemplo, que: "Desde este marco teórico sobre el que reflexionamos, intentamos buscar una definición acertada para el grupo de discusión. Esta tarea carece hoy en día de precisión y de formalización. Tal és así que para definir dicha técnica se utilizan aspectos manifiestos que caracterizan las situationes grupales. Ello lleva a que encontremos una diversidad de definiciones según el autor que se refiera a ella, y a que se le de un enfoque distinto en función de la orientación teórica de partida. Normalmente a la hora de definir la técnica se utilizan las características principales que comparte" (Ortega, 2005: 21).

3 A relevância que assume, neste tipo de técnica a perspectiva dos actores é explicada por Javier Callejo do seguinte modo: "Se debe estudiar la perspectiva de los actores porque forma parte da realidad social, de las relaciones sociales. Haciendo una arriesgada sintixis, tan realidad social es lo que existe como lo que los sujetos creen que existe [...]. La forma de ver los actores las cosas es parte de las cosas, construyéndolas. Los actores constituyen la realidad social en que actúan. La realidad social es, en cada caso, la que señalan los actores como su percepción. Para intervir: cambiar el comportamiento de los sujetos implica cambiar la percepción de los sujetos (actitudes, estruturas cognitivas), lo que exige conocerlas, tanto en su identificación como en su intensidad y profundidad, con lo que se desemboca en la importancia del vínculo con lo que se cree y lo que se dice. Algo difícil de observar a través de la encuesta" (Callejo, 2001: 38).

4 Magdalena Ortega, no seu trabalho, em virtude da diversidade de técnicas existentes para a recolha de informação (entrevista em grupo, entrevista em profundidade e histórias de vida) que podem confundir-se com o grupo de discussão, aponta algumas características distintivas inerentes a estas técnicas. Em síntese, sublinhamos as seguintes: "A diferencia más importante desta técnica [entrevista em grupo] com el grupo de discusión radica en que, en esta última, los/las participantes se preguntan, intercambian opiniones, puntos de vista, aclaran dudas... la discusión va así progresando y haciéndose cada vez más compleja y profunda. Se produce una interiorización y se va adquiriendo y construyendo un significado 'compartido'. Esto no llega a darse en la entrevista de grupo. [Na entrevista em profundidade não existe o processo de escuta mútua, a partir do qual] se construye el resultado del discurso, lo que no implica, por tanto, un habla (o diferentes hablas) indivuduales, sino una única con carácter grupal. [A história de vida] nos ofrece la visión diacrónica, cronológica o temporal, que no nos da el grupo de discusión. Éste se realiza en un único momento y en un determinado espacio de 
tiempo. [No entanto, esta autora é de opinião que estas técnicas] podem complementar de manera adecuada a la obtenida mediante el grupo de discusión" (Ortega, 2005: 41-43).

5 Convirá, contudo, acrescentar que em articulação com a utilização desta técnica pode sempre recorrer-se a outros indicadores sociais e fontes documentais ou outros dados que sirvam para explicar e complementar o contexto que se pretende estudar, no sentido de ajudar à compreensão dos "significados sociais" da realidade que se estuda e que o grupo vai construindo (cf. Ortega: 35 ).

6 Também alguns investigadores ingleses quando aludem à construção do corpus para a pesquisa referem-se ao critério da saturação. Assim, "saturação é o critério de finalização: investigam-se diferentes representações, apenas até que a inclusão de novos estratos não acrescente nada de novo" (Bauer, Gaskell \& Allum, 2002: 59).

\section{Referências}

BAUER, Martin W. ; GASKELL, Georges \& ALLUM, Nicholas C. (2002). Qualidade, quantidade e interesses do conhecimento. Evitando confusões. In M. W. Bauer \& G. Gaskell, Pesquisa Qualitativa com Texto, Imagem e Som. Pretópolis: Vozes: 17-36.

BURGESS, Robert G. (1997). A Pesquisa de Terreno. Uma Introdução. Oeiras: Celta.

CALLEJO, Javier (2001). El Grupo de Discusión: Introducción a una Prática de Investigación. Barcelona: Ariel.

FABRA, Maria Lluïsa \& DOMÈNECH, Miquel (2001). Hablar y Escuchar. Barcelona: Paidós.

GASKELL, George (2002). Entrevistas individuais e grupais. In M. W. Bauer \& G. Gaskell, Pesquisa Qualitativa com Texto, Imagem e Som. Pretópolis: Vozes: 6489.

ORTEGA, Magdalena (2005). El Grupo de Discusión. Una Herramienta para la Investigación Cualitativa. Barcelona: Laertes.

WOODS, Peter (1993). La Escuela por Dentro. La Etnografía en la Investigación Educativa. Barcelona: Paidós. 
THE STUDY OF THE SCHOOL UNIVERSE THROUGH THE VOICE OF THE YOUNG PEOPLE: THE DISCUSSION GROUP

\begin{abstract}
This text, centred on a research that took place in a specific school context, wants to stress the importance of using qualitative methodology for research and to show the inherent potencialities of the discussion group for data collection, mainly when the interlocutors are young secondary school students. The present article aims at focusing on some dimensions considered crucial to carry out field work using the discussion group. After a short incursion into some authors whose work has been privileging this technique of collecting information in the study of different socio-educational contexts, we develop a concise reflection about its potentialities and some of its limitations.
\end{abstract}

Keywords

Discussion group; Youngs; School universe; Experience

L'ÉTUDE DE L'UNIVERS SCOLAIRE À TRAVERS LA VOIX DES JEUNES: LE GROUPE DE DISCUSSION

Résumé

Ce texte, centré sur une recherche qui a eu lieu dans un certain milieu scolaire, vise mettre en relief l'importance de l'utilisation de la méthodologie qualitative dans la recherche et montrer les potentialités inhérents au groupe de discussion pour la récolte de l'information, surtout quand les participants ce sont des jeunes élèves du lycée. Cet article a l'intention de souligner quelques dimensions vues essentielles pour conduire un travail de recherche en utilisant 
le groupe de discussion. Après avoir fait une brève incursion sur quelques auteurs dont les travaux privilégient cette technique de récolte d'information pour l'étude de différents milieux socio-éducatifs, on fait une réflexion sommaire à propos de ses potentialités et de quelques uns de ses limites.

Mots-clé

Groupe de discussion; Jeunes; Univers scolaire; Expérience

Recebido em Fevereiro/2008

Aceite para publicação em Janeiro/2009

Toda a correspondência relativa a este artigo deve ser enviada para: Maria Cecília Pereira dos Santos, Rua Vasco da Gama, 101, 4420-576 Valbom, Gondomar, Portugal. 